\title{
Psicologia, Filosofia e meio ambiente: delineando o conceito de sustentabilidade afetiva
}

\section{Psychology, Philosophy and environment: outlining the concept of affective sustainability}

\section{Psicología, Filosofía y medio ambiente: delineando el concepto de sostenibilidad afectiva}

\author{
Sonia Regina Vargas Mansano* \\ Universidade Estadual de Londrina - UEL, Londrina, Paraná, Brasil \\ Paulo Roberto de Carvalho** \\ Universidade Estadual de Londrina - UEL, Londrina, Paraná, Brasil
}

\begin{abstract}
RESUMO
A preocupação com o meio ambiente e a manutenção de um planeta sustentável, cujos recursos naturais estejam acessíveis às próximas gerações, atravessa diferentes áreas de conhecimento e esferas governamentais. Políticas públicas, projetos de leis, movimentos sociais e iniciativas micropolíticas colocam a questão da sustentabilidade em evidência e procuram chamar a atenção da população para uma dificuldade crescente e urgente: a preservação da vida em nosso planeta. Atentando-se para essa realidade social, o presente artigo teórico tem por objetivo aproximar dois conceitos, estudando-os de maneira aprofundada: sustentabilidade e afeto. Serão duas as principais fontes utilizadas como referência deste estudo: para a noção de sustentabilidade, buscaremos respaldo nas obras de Elkington (2001), Foladori (2002) e Guattari (1997). Já para abordar o conceito de afeto, a obra de referência será a "Ética", de Espinosa (1677/1983), bem como os estudos de dois filósofos: Deleuze (2002, 2009) e Chauí (1995, 1999). Acreditamos que essa aproximação conceitual permitirá elaborar e fundamentar a noção de "sustentabilidade afetiva". Como conclusão parcial, o artigo evidencia que afeto e meio ambiente estão inter-relacionados e, uma vez articulados, podem promover questionamentos sobre a complexa relação que o humano estabelece com a natureza.
\end{abstract}

Palavras-chave: afeto, sustentabilidade, subjetividade, psicologia, filosofia.

\section{ABSTRACT}

The concern with the environment and the maintenance of a sustainable planet, whose natural resources are accessible for future generations, involves different areas of knowledge and government spheres. Public policies, bills, social movements and micropolitical initiatives put the issue of sustainability in evidence and seek to draw the attention of the population to an increasing difficulty and urgent: the preservation of life on our planet. Paying attention to this social reality, the present article aims at theoretical 
approach two concepts, studying them in-depth manner: sustainability and affection. Will be two major sources used as reference of this study: to the notion of sustainability, we will seek support in the works of Elkington (2001), Foladori (2002) and Guattari (1997). To address the concept of affection, the reference work is the "Ethics" of Espinosa (1677/1983), as well as the studies of two philosophers: Deleuze $(2002,2009)$ and Chauí (1995, 1999). We believe that this conceptual approach will make it possible to develop and substantiate the notion of "affective sustainability". As partial completion, the article shows that affection and environment are interrelated and, articulated, can promote complex concerns the human relationship establishes with nature.

Keywords: affection, sustainability, subjectivity, psychology, philosophy.

\section{RESUMEN}

La preocupación por el medio ambiente y el mantenimiento de un planeta sostenible, cuyos recursos naturales son accesibles para las generaciones futuras moviliza diferentes áreas del conocimiento y de las esferas de gobierno. Las políticas públicas, facturas, movimientos sociales e iniciativas micro políticas ponen la cuestión de la sostenibilidad en evidencia y tratan de atraer la atención de la población a una dificultad creciente y urgente: la preservación de la vida en nuestro planeta. Poniendo la atención en esta realidad social, el presente artículo tiene como objetivo acercar dos conceptos, estudiando la temática en profundidad: sostenibilidad y afecto. Serán dos las principales fuentes utilizadas como referencia de este estudio: en la noción de sustentabilidad, vamos a buscar apoyo en los trabajos de Elkington (2001), Foladori (2002) y Guattari (1997). Para abordar el concepto de afecto, la obra de referencia es la "Ética" de Espinosa (1677/1983), así como los estudios de dos filósofos: Deleuze $(2002,2009)$ y Chauí (1995, 1999). Creemos que este enfoque conceptual permitirá elaborar y fundamentar la noción de «sostenibilidad afectiva». Como conclusión parcial, el artículo muestra que afecto y medio ambiente están interrelacionados $y$, una vez articulados, pueden promover debates sobre las preocupaciones complejas que existen en la relación humana con la naturaleza.

Palabras clave: afecto, sostenibilidad, subjetividad, psicología, filosofía.

\section{I ntrodução}

Ao longo do século $X X$, a problemática da relação entre o humano e o meio ambiente ganhou motivos históricos para ser debatida no contexto acadêmico e pelas diferentes áreas de conhecimento. Depois de uma longa trajetória de apropriação do meio natural, realizada pelo homem, na qual a natureza foi sendo gradativamente colocada ao seu serviço, começa-se a evidenciar os efeitos da intervenção transformadora e, por vezes, predatória e catastrófica, que alcança dimensões planetárias (Stengers, 2015). A degradação ambiental, a destruição continuada de meios e recursos oferecidos pela natureza, bem como as evidências científicas do caráter finito desses recursos, criam as condições para afirmação de que o humano precisa transformar-se. Mas, em qual direção? Para o pensador 
contemporâneo Guattari, a direção é aquela em que o humano não experimente sua própria extinção por efeito das intervenções provocadas por ele próprio. Guattari salienta:

Sem uma reorientação radical dos meios e, sobretudo, das finalidades da produção, é o conjunto da biosfera que ficará desequilibrado e que evoluirá para um estado de incompatibilidade total com a vida humana e, aliás, mais geralmente, com toda forma de vida animal e vegetal (Guattari, 1992, p. 172).

Como, porém, a Filosofia e a Psicologia poderiam participar desse debate político? Em um mundo subjugado pelo peso das determinações econômicas, pelo imperativo da taxa de lucro e pelo acúmulo desmesurado de capital, cabe indagar o que caberia a essas áreas de conhecimento. Em sua obra "O que é a Filosofia?", Deleuze e Guattari consideram: "a filosofia é a arte de formar, de inventar, de fabricar conceitos" (Deleuze \& Guattari, 1992, p. 10). Mas, e quanto ao conceito, esse elemento propriamente filosófico, o que é possível dizer dele? Os autores explicam: "Não há conceito simples. Todo conceito tem componentes, e se define por eles. Tem, portanto, uma cifra. É uma multiplicidade" (Idem, p. 27). Dessa maneira, criar ou construir um conceito comporta o processo de articulação de componentes advindos de distintas áreas assim como de outros conceitos.

Dando sequência à definição do que é a Filosofia, os autores assinalam que a criação do conceito, como tarefa propriamente filosófica, responde a um problema do qual esta criação é inseparável. Ou ainda: "Todo conceito remete a um problema, a problemas sem os quais não teria sentido, e que só podem ser isolados ou compreendidos na medida de sua solução" (Idem, p. 278). Reunimos, então, os elementos necessários para retornarmos ao problema inicial desta investigação e que concerne às relações entre o humano e o meio ambiente. Um problema que permanece por séculos e que hoje ganha contornos catastróficos, uma vez que a destruição dos recursos e das espécies naturais pode ser um dos precedentes para o desaparecimento do próprio homem (Diegues, 2010; Stengers, 2015).

O conceito que se pretende delinear neste artigo teórico, partindo das contribuições da Filosofia e da Psicologia, é o de sustentabilidade afetiva. Para isso, o estudo buscou analisar cada um de seus componentes de maneira separada, bem como explorar o que está implicado em sua elaboração. Para abordar estas questões, o estudo foi dividido em três momentos: primeiramente, abordaremos a noção de sustentabilidade e suas vinculações com a preservação do planeta, verificando como isso está diretamente implicado na construção dos 
modos de viver. Utilizaremos como referência as obras de Elkington (2001), Foladori (2001, 2002) e Guattari (1997). Em seguida, daremos ênfase ao conceito de afeto, buscando compreender seus desdobramentos relacionais, recorrendo às análises de dois filósofos contemporâneos, Deleuze $(2002,2009)$ e Chauí (1995, 1999), que dedicaram parte de seus estudos à compreensão da obra denominada "Ética", de Espinosa (Espinosa, 1677/1983). No campo da Psicologia, resgatamos os estudos de Rolnik (2003) e Fonseca (2013) que colocam para a área o desafio de compreender os afetos em sua dimensão vibrátil, perspectiva e múltipla. Por fim, elaborando algumas aproximações conceituais, circunscrevemos a infinita série das relações de afetação que compõem nossas vidas. Tal estudo justifica-se, assim, por enfatizar a dimensão política sobre a distância que existe entre o mundo que temos e aquele que desejamos.

\section{Sustentabilidade: uma noção recente}

A sustentabilidade comparece neste estudo como um dos componentes conceituais a ser tomado em análise. Polêmica entre os pesquisadores que se dedicam à sua investigação, a noção de sustentabilidade aparece comumente associada às questões ligadas ao meio ambiente e à preservação da natureza (Lenzi, 2006; Foladori, 2001, 2002). Os estudiosos que problematizam a sustentabilidade anunciam suas preocupações com a preservação dos recursos naturais do planeta e com o avanço da devastação, sendo este último justificado de maneira arriscada pelo desenvolvimento econômico e pela produção de riquezas.

No último século, mais precisamente em sua segunda metade, disseminou-se uma inquietação social e política no sentido de colocar limites na exploração dos recursos naturais com vistas a garantir o seu uso coletivo no presente, mas também estender suas possibilidades de acesso às gerações que estão por vir. Em 1987, foi apresentado à ONU (Organização das Nações Unidas) o documento denominado "Nosso Futuro Comum", que também ficou conhecido como "Relatório Brundtland", uma vez que foi elaborado sob a coordenação da diplomata norueguesa Gro Harlem Brundtland. Este relatório concebe o desenvolvimento sustentável como algo que "satisfaz as necessidades presentes, sem comprometer a capacidade das gerações futuras de suprir suas próprias necessidades" (Brundtland, 1991). Depois da sua ampla disseminação, diversos movimentos sociais, conferências, projetos de leis e campanhas publicitárias ganharam destaque mundial e o tema passou a ser debatido em contextos locais e fóruns internacionais. Compete mencionar que o relatório também foi bastante criticado por evidenciar seus limites quanto à implementação, bem como de 
implicar agentes sociais e países em sua execução (Misoczky \& Böhm, 2012).

Já em 1990, o sociólogo britânico Elkington apresentou a expressão "Triple Bottom Line" por meio da qual pretendeu levar a discussão a respeito da sustentabilidade para o âmbito das empresas. Com isso, ele buscava elaborar um mecanismo para quantificar e analisar os impactos da produção de bens sobre a natureza, tomando em consideração três aspectos: o social, o econômico e o ambiental (Elkington, 2001). O denominado tripé da sustentabilidade, por ele proposto, tinha como foco a mudança do modelo de negócio tradicional com vistas a expandir um novo modelo econômico que, mantendo a ênfase no lucro, buscasse, ao mesmo tempo, ganhar adesão e simpatia tanto do consumidor quanto da comunidade na qual a empresa estivesse localizada. Assim, as empresas poderiam conquistar uma parcela dos consumidores que se mostrava preocupada com a natureza e estava disposta a dirigir o consumo para produtos supostamente comprometidos com a preservação. Autores como Almeida (2002) e Kraemer (2005) também fazem uma articulação da noção de sustentabilidade com a esfera empresarial, sublinhando suas possibilidades e limitações.

As chances concretas de viabilização dessas propostas, entretanto, são amplamente questionadas (Misoczky \& Böhm, 2012), tendo em vista que as ideias de lucro e preservação coexistem, muitas vezes, de modo conflituoso. Cabe, então, considerar que existe uma dimensão de crise na constituição desta visão tridimensional, tal como Foladori assinala.

Essa apresentação da tridimensionalidade da sustentabilidade é atrativa e parece abranger os diferentes setores nos quais 0 desenvolvimento capitalista deve focar sua atenção. Porém, “(...) trata-se de uma visão tecnicista e, portanto, ideologicamente comprometida com o próprio capitalismo causador da degradação" (Foladori, 2002, p. 105).

Tal como fica evidente na fala do autor, a contradição entre a preservação e a obtenção do lucro não se resolve na proposta do Triple Bottom Line. Ao contrário, termina por reafirmar a predominância da esfera econômica, reservando para as problemáticas ambiental e social um plano secundário, que acaba funcionando apenas para fins de autopromoção publicitária das empresas (Foladori, 2001; Misoczky \& Böhm, 2012).

Deleuze e Guattari, em sua obra "O Anti Édipo: esquizofrenia e capitalismo" (1972/2010), já mostravam o quanto o capital atua anexando diferentes dimensões da vida em sociedade ao seu próprio regime de funcionamento e também aos seus objetivos materiais e econômicos. No entendimento dos autores, o capital opera por uma axiomatização: ele busca inscrever sujeitos, grupos, acontecimentos e movimentos sociais em sua própria lógica, priorizando a geração de 
lucro, independentemente de um dado segmento de mercado já ter sido ou não explorado. Para operar a axiomatização, esse sistema socioeconômico mantém seus agentes "atentos às oportunidades" capazes de reverterem-se em um nicho, observando situações comuns e corriqueiras que possam vir a ser inscritas na sua dinâmica. Dizem Deleuze e Guattari: “A verdadeira axiomática é a da própria máquina social, que substitui as antigas codificações, e que organiza todos os fluxos descodificados, inclusive os fluxos de código científico e técnico, em proveito do sistema capitalista e a serviço dos seus fins" (Deleuze \& Guattari, 1972/2010, p. 310).

É assim que a crise ambiental e a proposta de uma sustentabilidade na perspectiva apresentada por Elkington mostram-se, antes de tudo, axiomatizadas, ou seja, ganham contornos de uma oportunidade a ser explorada pelo mercado. Para um sistema que tem como foco a neutralização de qualquer iniciativa que incorpore uma dimensão de ruptura, sempre é possível detectar um campo inexplorado pela produção capitalista, não importando suas características, procedimentos ou implicações sociais. Os autores assinalam ainda: "Quanta flexibilidade na axiomática do capitalismo, sempre pronto a ampliar seus próprios limites para acrescentar mais um axioma a um sistema já saturado" (Idem, p. 317), estando localizado precisamente neste acréscimo ininterrupto a "potência dessa economia" (Idem, p. 332). É assim que a sustentabilidade torna-se, também ela, um nicho de mercado a ser explorado. E, atuando dessa maneira, passa a funcionar como um indicador da legitimidade de outros nichos que, agora, ganham a denominação de sustentáveis.

Entretanto, é notável nos estudos de Lenzi que a noção de sustentabilidade vem sendo abordada de múltiplas maneiras, nas quais estão presentes objetivos distintos, dependendo da vertente teórica que a examina. O autor mostra ainda que tais iniciativas cooperam para assinalar a urgência da questão ambiental: "se não mantivermos um padrão mínimo de qualidade da atmosfera, dos solos, dos recursos hídricos, a possibilidade de satisfazer necessidades humanas básicas poderá ficar comprometida" (Lenzi, 2006, p. 106).

Considerando as polêmicas conceituais produzidas pelas diferentes áreas de conhecimento que se dedicam ao estudo do meio ambiente, cabe explorar outro ângulo de análise e compreender a sustentabilidade a partir da própria palavra e das suas derivações. Nessa direção, constatamos que o verbo "sustentar" vem do latim, sustentare e significa "evitar a queda, manter o equilíbrio de, suster(se); apoiar(-se); manter a resistência a; resistir; aguentar(-se)" (Houaiss, 2009, p. 2797). Essa ampla variedade descritiva, que guarda inclusive divergências entre si, facultou-nos a delimitar sua acepção e dirigir o uso do termo sustentar, no contexto deste estudo, especificamente para o sentido de apoiar. A sustentabilidade, como 
um adjetivo, consiste em oferecer condições a algo ou a alguém para dar prosseguimento à tarefa de existir no mundo. Foi nessa perspectiva que passamos a investigar o que teríamos a apoiar nas diferentes dimensões da existência, incluindo aí o objeto do presente estudo: a natureza e as relações afetivas que nos atravessam.

Um indício de resposta foi constatado na crescente preocupação com o planeta que tem chamado à atenção de diferentes segmentos sociais, passando a ser debatida em escala planetária, pelas conferências internacionais, na formulação de políticas públicas, nas universidades, nas organizações não governamentais, nos blogs e mesmo em situações da vida cotidiana. Nota-se, com isso, que o debate sobre a problemática ambiental amplia gradativamente seu domínio e se coloca para além da manutenção dos recursos naturais básicos. Aos poucos, é possível constatar que a sustentabilidade passa a ser analisada também em suas dimensões políticas e afetivas. Nas palavras de Guattari:

O que está em questão é a maneira de viver daqui em diante sobre esse planeta, no contexto da aceleração das mutações técnico-científicas e do considerável crescimento demográfico. Em função do contínuo desenvolvimento do trabalho maquínico redobrado pela revolução informática, as forças produtivas vão tornar disponível uma quantidade cada vez maior do tempo de atividade humana potencial. Mas com que finalidade? A do desemprego, da marginalidade opressiva, da solidão, da ociosidade, da angústia, da neurose, ou a da cultura, da criação, da pesquisa, da re-invenção do meio ambiente, do enriquecimento dos modos de vida e de sensibilidade? (Guattari, 1997, p. 8).

Entendemos que aquilo que confronta uma vertente (a da exploração predatória) com a outra (a da invenção dos modos de vida) é precisamente a noção de sustentabilidade. A preocupação com o planeta evoca não apenas uma atenção à preservação dos recursos naturais, mas também dos próprios humanos, com seus modos de viver, de sentir e de se relacionar com os outros - sejam esses outros as pessoas, a natureza e o leque diversificado das produções sociais (arte, conhecimento, tecnologia, informações, imagens e valores).

O que torna a análise dessa problemática da relação entre humano e natureza difícil e complexa é a presença dos mais variados elementos subjetivos e afetivos que nela comparecem e que nem sempre encontram espaço de expressão e problematização. E, para além deles, contamos também com componentes econômicos, políticos e tecnológicos que complexificam ainda mais esse campo, multifacetado e dinâmico. O fato é que, neste momento histórico, já não podemos tratar a problemática da sustentabilidade como uma 
questão irrelevante, uma vez que seus efeitos estão sendo sentidos pela população, que já sofre com a depredação contínua da natureza em sua existência cotidiana. Seus efeitos também são sentidos no âmbito das relações sociais. Nessa direção, Guattari assinala:

As formações políticas e as instâncias executivas parecem totalmente incapazes de apreender essa problemática no conjunto de suas implicações. Apesar de estarem começando a tomar uma consciência parcial dos perigos mais evidentes que ameaçam o meio ambiente natural de nossas sociedades, elas geralmente se contentam em abordar o campo dos danos industriais e, ainda assim, unicamente numa perspectiva tecnocrática, ao passo que apenas uma articulação éticopolítica - a que chamo ecosofia - entre os três registros ecológicos (o do meio ambiente, o das relações sociais e o da subjetividade humana) é que poderia esclarecer convenientemente tais questões (Guattari, 1997, p. 8).

Os três registros (ou três ecologias) analisados pelo autor (que envolvem o meio ambiente, as relações sociais e a produção de subjetividades) evidenciam que, para além dos conhecimentos técnicos e científicos sobre o meio ambiente, das iniciativas advindas da iniciativa privada e das ações governamentais para legislar sobre essa questão, torna-se decisivo tomar em análise também os processos subjetivos que se fazem presentes na construção de práticas ecológicas e sustentáveis. Processos esses que envolve ações microssociais, por vezes menores e imperceptíveis, mas que possuem a potência de produzir pequenas fissuras no modo dominante e antropocêntrico de se relacionar com o meio ambiente e a vida (Godoy, 2008; Stengers, 2015).

É nesse contexto que introduzimos em nosso estudo a linha conceitual dos afetos. Antes de passar para a análise preliminar desse conceito, porém, cabe ressaltar que das três ecologias propostas por Guattari, duas delas são voltadas para as relações sociais, nas quais a questão do afeto se evidencia. Assim, ao transitar da abordagem ecológica focada na preservação do meio ambiente, em direção a uma ecologia afetivo-relacional que comporte uma análise crítica sobre o tipo de vida que estamos ajudando a construir, Guattari dá visibilidade ao problema do empobrecimento afetivo e relacional.

\section{A respeito do afeto e das variações do corpo}

Para o contexto deste estudo, partimos do conceito de afeto tal como ele aparece nos estudos de Deleuze (2002, 2009) e Chauí (1995, 1999) sobre a obra de Espinosa. Seguimos também a apropriação 
desse conceito tal qual realizada pela Psicologia, acompanhando os estudos de Rolnik (2003) e Fonseca (2013). De acordo com Espinosa, a noção de encontro perpassa toda existência social, sendo esse um elemento distintivo que nos coloca em contato com os afetos e as diferenças inerentes à vida em sociedade. Os encontros são a condição para nos produzirmos como humanos. Eles implicam variações afetivas que podem ir, de acordo com o autor, da alegria, com o aumento da potência, em que o corpo sente-se mais forte e aberto para o encontro; ou pode seguir na direção da tristeza, pela qual se experimenta uma baixa intensidade, um desânimo, um fechamento para o contato social. Ao estudar os afetos, Deleuze assinala que "alguma coisa em mim não cessa de variar" (Deleuze, 2009 , p. 25). Essa "alguma coisa" manifesta-se no corpo que, por sua vez, é compreendido como "uma linha melódica de variação contínua" (Idem, p. 26).

Nesse sentido, vivemos em uma variação afetiva que ora compõe o corpo (aumentando a sua potência), ora o decompõe (diminuindo a potência). $\mathrm{Na}$ iminência e acaso dos encontros, a potência do corpo varia, uma vez que não a possuímos de uma vez por todas. Assim, para Espinosa, o corpo é uma porta de contato com o mundo e as variações afetivas experimentadas dão indícios de nossas conexões com aquilo que nos cerca.

Podemos seguir com Deleuze que, analisando os efeitos dos encontros nos corpos, assinala:

Será dito bom (ou livre ou razoável ou forte) aquele que se esforça, tanto quanto pode, para organizar os encontros, por se unir ao que convém à sua natureza, por compor a sua relação com relações cambiáveis e, por esse meio, aumentar sua potência (Deleuze, 2002, p. 29).

Como os encontros guardam uma dimensão de acaso, sem muito espaço para controle e previsão, Deleuze acrescenta: "No encontro ao acaso entre os corpos podemos selecionar a ideia de certos corpos que convêm com o nosso e que nos dão alegria" (Deleuze, 1997, p. 167). Ora, nesse caso, o sujeito já não se encontra tão passivo e sujeitado ao acaso, mas tem condições de experimentar a variação da potência do corpo por efeito dos encontros, esforçando-se para ir adiante, compreendendo as causas desses efeitos e, principalmente, abrindo-se a possibilidade de selecionar aqueles que the convém. Entretanto, mais à frente, Deleuze alerta: “Essa seleção é muito dura, muito difícil. É que as alegrias e as tristezas, os aumentos e as diminuições, os esclarecimentos e os assombramentos costumam ser ambíguos, parciais, cambiantes, misturados uns aos outros" (Idem, p. 163). O que exige, para Deleuze, "um trabalho de vida" (Deleuze, 2009, p. 51), um exercício político que busca "compreender de 
maneira vital em que tal ou tal corpo desconvém e não mais convém" (Idem) com o nosso.

Mas não seria assim também em relação ao meio ambiente natural, do qual o humano encontra-se cada vez mais distanciado e do qual ele necessita precisamente para manter-se e expandir sua própria potência? Não estaria a humanidade, neste momento histórico, desconsiderando as afetações referidas à relação com a natureza e admitindo sofrer, de modo passivo e indiferente, as consequências advindas da industrialização e do avanço tecnológico sob a égide do capital? Nesse contexto, Deleuze considera que o humano, por vezes, contenta-se "em sofrer as consequências, pronto a gemer e a acusar toda vez que o efeito sofrido se mostra contrário e lhe revela a sua própria impotência" (Deleuze, 2002, p. 29).

Acreditamos que a análise dos afetos, tal como pensada por Espinosa, também pode ser estendida ao contexto das relações entre o humano e a natureza. Trata-se da experimentação de afetações recíprocas, em algumas ocasiões quase imperceptíveis, mas que operam mudanças significativas no humano e na natureza, uma vez que cada "corpo é afetado de muitas maneiras" (Espinosa, 1677/1983, p. 136). Tomar em análise as composições e decomposições dos afetos geradas sobre os corpos (do humano e da natureza) envolve uma dimensão política. Assim, é a experiência das afetações que permite considerar a constituição de novos modos de subjetivação relacionados à questão ambiental: novos modos de sentir e de pensar, distantes da indiferença já assinalada por Guattari como sendo uma "passividade fatalista" (Guattari, 1997, p. 9) que aceita como inevitáveis a destruição sistemática do planeta. Nesse processo de afetação mútua e imanente, humano e natureza são tomados em consideração na singularidade que os atravessa (Viveiros de Castro, 2015).

Outro aspecto a ser considerado sobre a obra de Espinosa é que a consistência de um encontro é permanentemente testada pelo corpo e por sua potência variável de afetação, ou seja, na sua força de conectar, romper, construir, destruir e/ou inventar as relações, inclusive com o meio ambiente. Isso torna o viver um exercício eminentemente político e arriscado. Seguindo esta perspectiva de análise, Chauí salienta:

A virtude do corpo é poder afetar de inúmeras maneiras simultâneas outros corpos e ser por eles afetado de inúmeras maneiras simultâneas “( $\ldots)$. A originalidade inovadora de Espinosa está em considerar que essas possibilidades e esse processo são dados pelos próprios afetos e não sem eles ou contra eles" (Chauí, 1995, p. 69-70). 
Entretanto, ao realizar uma análise do conceito de afeto nesta perspectiva mutante, notamos que nem sempre as variações afetivas, precipitadas na relação com a natureza, mas também, nos encontros com a sociedade, podem ser vividos e sentidos como "uma virtude" (I dem). As variações afetivas, nessas duas situações, podem resultar, tal como considerado por Espinosa, tanto em composição quanto em decomposição. Trata-se de um campo tensionado que, tal qual se pretende evidenciar neste estudo, é simultaneamente ambiental e social, cuja dinâmica pode ser reconhecida em diversas dimensões da existência. Analisaremos aqui duas delas a título de exemplificação: as relações de trabalho e as relações amorosas.

O contexto laboral é marcado pelos mais variados encontros que, por vezes, enfraquecem e despotencializam os trabalhadores, à medida que as diferenças precisam ser "neutralizadas" em nome do tão promulgado "bom atendimento". O que temos nesse caso? Um corpo tornado dócil que é permanentemente solicitado a anestesiar e "desativar" (Rolnik, 2003, p. 80) ou, pelo menos, minimizar os impactos dos afetos que experimenta, mantendo-se em uma espécie de regularidade afetiva que, desde uma perspectiva espinosana, é impossível.

Ainda assim, em muitas situações profissionais, essa regularidade afetiva é exigida como um diferencial a ser oferecido pelo trabalhador ao cliente. Nesse caso, cabe questionar: O que fazemos do corpo de quem trabalha quando exigimos que ele se mantenha afetivamente disponível para receber o cliente que, por vezes, inicia o encontro descarregando queixas, agressividade e ressentimento? Será que o corpo do trabalhador é capaz de manter-se imune à variação afetiva inerente aos encontros? Certamente não. Porém, o que se percebe nas relações de trabalho que envolvem o contato direto com clientes é precisamente uma expectativa contrária à variação, qual seja, a demanda/exigência de que o corpo do trabalhador mantenha-se "em equilíbrio" e sempre pronto para atender o cliente de maneira de padronizada. Em larga medida, o trabalhador recebe uma espécie de "prescrição de afetos" a ser seguida no decorrer de sua jornada de atividade. Sob o ponto de vista do empregador e/ou do cliente, as prescrições envolvem: o sorriso, a cordialidade e a atenção personalizada, independentemente dos afetos experimentados no encontro com seu interlocutor.

Essa situação, que evidencia a dificuldade para acolher e sustentar a variação afetiva dos corpos, estende-se para além do trabalho, chegando também às relações mais íntimas. A variação dos afetos nas relações amorosas tende a ser acompanhada de uma avaliação frequentemente negativa. Assim, diante de uma mudança afetiva do companheiro, logo se enuncia: "Você está com algum problema?"; "O que está acontecendo?". Ora, se partimos da ideia de que a vida é da ordem dos afetos, a variação lhe é inerente. Porém, o sujeito que 
experimenta e demonstra as variações afetivas, não prescritas e/ou previstas (que, como já mencionado, vão da alegria à tristeza, podendo se compor de múltiplas maneiras), corre o risco de ser taxado de instável, descontrolado, agressivo ou até mesmo doente.

Novamente, o que vemos se instalar é a simplificação da dimensão afetiva da existência que, sob o ponto de vida de uma suposta linearidade (bastante idealizada e, portanto, inatingível), deveria manter-se adequada para receber o outro e relacionar-se com ele de maneira "estável", independentemente das variações que são experimentadas nos corpos o que, vale recordar, na leitura de Chauí comporta uma virtude. Pode-se dizer que a dificuldade para sustentar tais variações dá indícios da insustentabilidade afetiva que ora experimentamos em diferentes âmbitos da vida relacional.

O que haveria em comum entre as problemáticas do meio ambiente, do trabalho e das relações amorosas que acabamos de descrever? Trata-se, em cada uma delas, de ter em perspectiva que os afetos implicam um campo mutante, tenso, gerador de composição e/ou decomposição. Trata-se também de reconhecer que podemos aproximar a composição da sustentabilidade, assim como a decomposição da insustentabilidade ou, em outras palavras, de uma destruição que se opera no plano das relações sociais, das variações afetivas e do planeta.

Mas, o que teríamos a sustentar no campo dos afetos? Ao assumirmos uma perspectiva espinosana, em diálogo tanto com a Filosofia quanto com a Psicologia, trata-se de sustentar o corpo em sua potência de variação afetiva ao invés de absorver passivamente as demandas por regularidade, prescrição dos afetos e degradação acelerada da natureza, advindas, em grande parte, da ordem socioeconômica atual. Nesse sentido, coloca-se a possibilidade de conexão com a natureza por múltiplas vias, incluindo a dos afetos. Rolnik (2003, p. 79) afirma que conhecer o mundo por meio dos afetos "convoca a sensação, engendrada no encontro entre o corpo e as forças do mundo que o afetam". Tais forças são díspares e, quando suficientemente intensivas, acionam sensibilidades e afetos que podem estar sufocados no cotidiano conturbado das relações urbanas. A autora acrescenta: "Aquilo que do corpo é afetável por estas forças não depende de sua condição de orgânico, de sensível ou sensorial, de erógeno, nem de emocional, mas de sua condição de carne percorrida por onda nervosa: um 'corpo vibrátil' (ou corpo intensivo)" (I dem). Assim, questionamos: Como o sujeito se ocuparia da problemática da natureza em suas relações sociais e afetivas se estas são vividas em meio ao empobrecimento, sufocando sua expressão?

Tal como já assinalado no início, a criação do conceito de sustentabilidade afetiva responde a uma dada condição problemática que se pretende colocar em evidência, reunindo, para isso, os dois 
componentes e possibilitando o olhar sobre o objeto conceituado. Uma vez construído o conceito, trata-se, agora, de dar visibilidade à problemática que ele responde. Em termos gerais, a sustentabilidade afetiva responde às condições atuais de uma vida social insustentável, seja na relação com a natureza, seja nas relações sociais e afetivas cotidianas.

\section{Por uma sustentabilidade afetiva}

Em seu livro "O Mínimo Eu: sobrevivência psíquica em tempos difíceis", Lasch (1987) argumenta que nosso tempo histórico é marcado pela expansão do que ele denominou "cultura do narcisismo", sendo esta caracterizada pelo individualismo, pelo declínio da preocupação com as questões que afetam a coletividade, pela dimensão política das relações sociais e pelo consumo de massa. No cenário descrito pelo autor, deixamos de experimentar um modo de vida relacional mais diversificado e público quando adotamos uma "mentalidade da sobrevivência" (1987, p. 51), na qual ganha destaque o fechamento nas relações intimistas, o controle do tempo, a busca por produtividade e a preocupação com a segurança individual. Para Lasch, estas dimensões são valorizadas cada vez mais frequentemente em nossa sociedade, em prejuízo dos encontros sociais e afetivos. Assim, assinala o autor:

Em uma época carregada de problemas, a vida cotidiana passa a ser um exercício de sobrevivência. Vive-se um dia de cada vez. Raramente se olha para trás, por medo de sucumbir a uma debilitante nostalgia; e quando se olha para frente, é para ver como se garantir contra os desastres que todos aguardam (Lasch, 1987, p. 9).

Em consonância com esse diagnóstico sobre a vida contemporânea, nota-se que as relações sociais têm sofrido mudanças valorativas aceleradas que não necessariamente são acompanhadas por processos de elaboração e análise quanto a seus efeitos subjetivos, afetivos e políticos, por mais que exista certo esforço nesse sentido. Em seu lugar, tornam-se frequentes enunciados do tipo: "Isso não me diz respeito", "Não adianta fazer nada" ou "A vida é assim mesmo", os quais podem ser compreendidos como uma espécie de resignação e indiferença coletiva que ganha força diante da constatação de que as mudanças no tecido social são lentas e nem sempre apresentam resultados satisfatórios. Continua Lasch: "Em tais condições, a individualidade transforma-se numa espécie de bem de luxo, fora de lugar em uma era de iminente austeridade (...). Sob assédio, o eu se contrai num núcleo defensivo, em guarda diante da 
adversidade" (Lasch, 1987). Pode-se dizer que nesse cenário ocorre a intensificação de uma solidão negativa e excludente (Fonseca, 2013). Em meio a esse recolhimento defensivo, que produz efeitos subjetivos restritivos nos modos de vida atuais, é que este estudo criou condições para aprofundar-se nos seguintes pontos: É possível pensar a vida relacional e afetiva para além da mera sobrevivência? Diante da tendência defensiva de fechar-se nos encontros intimistas é possível vislumbrar uma vida relacional mais rica e diversificada, incluindo aí a relação com a natureza? Como as relações de afeto, vividas no campo social, podem se conectar com a preservação do planeta em um contexto marcado pela indiferença? E, nesse sentido, como fazer coincidir sobre um mesmo corpo conceitual as noções de sustentabilidade e afeto, de modo a problematizar nossa relação com a natureza nos encontros que ora experimentamos?

As questões aqui colocadas, bem como aquelas evidenciadas por Lasch, podem preliminarmente ser caracterizadas como um empobrecimento afetivo e relacional que gera diversas configurações para a sensação de solidão (Fonseca, 2013), uma das marcas da contemporaneidade capitalista. Esse empobrecimento (insustentável) distribui-se por diferentes contextos da vida em sociedade. Ao fechamento que o autor assinala no âmbito da vida privada, somamse os ambientes de trabalho nos quais transcorre uma parcela do tempo de vida dos sujeitos. Neles, a vida social e afetiva também se apresenta empobrecida. Os sujeitos, nesse contexto, constituem-se a partir de modos previamente definidos do pensar, do agir e do sentir perante a vida. Guattari e Rolnik destacam o empobrecimento da vida inscrita nos modos de subjetivação capitalísticos:

Os indivíduos são reduzidos a nada mais do que engrenagens concentradas sobre o valor de seus atos, valor que responde ao mercado capitalista e seus equivalentes gerais. São espécies de robôs, solitários e angustiados, absorvendo cada vez mais as drogas que o poder lhe proporciona, deixando-se fascinar cada vez mais pela promoção (Guattari \& Rolnik, 1996, p. 40).

Eis, aqui, o estado de coisas que o conceito de sustentabilidade afetiva quer colocar em evidência para o exercício da crítica. A variação afetiva, inerente à condição humana, perde-se no contexto de uma subjetividade capitalística que seleciona determinados componentes subjetivos, excluindo outros. Mais ainda, ao final desse processo, é a própria concepção do que é a vida que acaba sendo redefinida em função da hegemonia do capital. Nas palavras de Guattari e Rolnik:

É uma subjetividade que não conhece dimensões essenciais da existência como a morte, a dor, a solidão, o silêncio, a relação 
com o cosmos, com o tempo. Um sentimento como a raiva é algo que surpreende, que escandaliza. Da mesma forma, uma doença incontrolável como o câncer é algo que nos deixa perplexos. O mesmo se dá com relação à velhice (Guattari \& Rolnik, 1996, p. 43).

A tentativa contemporânea de excluir certas dimensões da existência que não se enquadram nos interesses de produtividade capitalista simplesmente nos distancia da própria vida e de suas mutações. Se a morte, a doença, a solidão e a velhice escandalizam, podemos encontrar nessa reação um indício da distância que guardamos para com a natureza, que atualiza tais movimentos cotidianamente. Esse distanciamento para com as "dimensões essenciais da existência" (Idem) não seria um indício da insustentabilidade que cerca permanentemente a subjetividade contemporânea?

Caminhando para uma construção conceitual que comporta os campos da sustentabilidade e do afeto, acreditamos que a sustentabilidade afetiva envolva necessariamente o corpo e suas variações afetivas, que se desdobram em aberturas e fechamentos para encontros de diferentes tipos, incluindo o encontro com a natureza. Como pensar a preservação do planeta e da natureza se o cuidado para com o próprio corpo e com sua potência afetiva tende a acontecer de maneira defensiva e privada em nossos dias? Talvez, um dos passos a ser dado em direção a uma sustentabilidade afetiva seja precisamente sensibilizar o corpo e sua força vital para experimentação dos encontros e das variações afetivas que eles colocam em curso. E por meio dessa ativação, atentar para sua potência de ação diante daquilo que Ihe advém. Trata-se, para Fonseca (2013, p. 210) de uma aproximação daquilo que é tido como estranho, uma "abertura às suas forças, uma simpatia, uma gentileza, uma amizade com as forças díspares que pedem passagem".

A prática capitalista da anestesia sistemática do corpo (Rolnik, 2003), que acontece especialmente pelas vias do descrédito, do individualismo e da indiferença, passando pela busca cega do acúmulo e da sobrevivência, possivelmente seja hoje nossa maior dificuldade, tendo em vista o grau de defesa psíquica que, segundo Lasch, nos encontramos atualmente. Consideramos que a Psicologia, como área de conhecimento voltada para a compreensão das relações humanas, tem condições de cooperar na elaboração desta análise, valendo-se do afeto como ferramenta conceitual, mas também explorando sua interface com a natureza.

Assim, entendemos que sustentar a diferença, a variação afetiva e o acaso dos encontros, longe de envolver uma simples prescrição, implica uma experimentação cotidiana que ganha contornos políticos, tendo em vista o fato de envolver práticas situadas, por vezes 
menores (Godoy, 2008), que possam ser dialogadas, analisadas e agenciadas em um exercício trabalhoso de produção de si, mas também da coletividade e da relação desta com a natureza. É precisamente essa construção conceitual e prática que está em questão.

\section{Considerações finais}

Chegando ao final deste percurso teórico, acreditamos que a Psicologia e a Filosofia têm muito a colaborar com o debate sobre a relação entre o humano e o meio ambiente. Nesse sentido, delineouse o conceito de sustentabilidade afetiva, definindo-o como a potência para apoiar e favorecer a variação dos afetos no corpo em função dos encontros vividos no cotidiano. Tal delineamento serviu para articular questões que dizem respeito ao meio ambiente e às relações afetivas, abrindo um campo de debate multidisciplinar sobre as condições em que a existência se encontra hoje.

Tal como já assinalado, a criação do conceito de sustentabilidade afetiva respondeu a uma dada condição problemática que se pretendeu colocar em evidência, reunindo, para isso, os dois componentes e possibilitando o olhar sobre o objeto conceituado. A variação afetiva e a ação diante dela, tal como visto com Espinosa, envolvem uma dimensão vital, tendo em vista que cada novo encontro, suficientemente intensivo, provoca mutações, por vezes incômodas e inesperadas.

Tomando em perspectiva o olhar espinosano, (apropriado tanto pela Filosofia quanto pela Psicologia) a sustentabilidade afetiva coloca em evidência a radicalidade da condição relacional a que estamos expostos. Corpos em meio a outros corpos, sem dúvida. Mas, principalmente, corpos potentes ao ponto de afetarem e serem afetados. Tal concepção possibilita entrever como é frágil e inconsistente a separação entre mundo humano e mundo natural, uma vez que ambos comportam afetações recíprocas e continuadas. Assim, até mesmo nossa condição de corpos individuados acaba sendo definida pela situação relacional, pelas conexões que, visíveis ou não, estabelecem-se entre os mesmos corpos. A sustentabilidade afetiva é um conceito que convoca a pensar sobre a infinita série das relações de afetação que compõe nossas vidas. Tomá-la em análise significa, assim, manter uma abertura para heterogeneidade das afetações. Seremos sensíveis a esse ponto? Teremos a potência de acolher o mundo com o grau de complexidade que ele abriga e nos oferece? A sustentabilidade afetiva, como uma ferramenta conceitual, apoia-se na teia dos encontros e das afetações para sinalizar a possibilidade de novos modos de existir a serem constituídos. 
Trata-se, assim, de acolher a complexidade da existência, experimentando as variações afetivas que esse processo comporta, fazendo-se sensível indistintamente ao humano e ao natural e, assim, percorrer uma série de intensidades que emergem neste processo. A esses movimentos poderíamos simplesmente chamar vida. Uma vez que optamos pela denominação sustentabilidade afetiva, foi para responder ao problema contemporâneo de uma existência anestesiada e indiferente àquilo que se passa ao seu redor. Trata-se de uma resposta tímida, dada à magnitude do problema a que responde: nos quatro cantos do planeta os humanos resignam-se, considerando a destruição dos recursos naturais e das sociedades humanas algo irreversível, já dado, sem qualquer possibilidade de intervenção e/ou variação. E, diante dessa manifestação de impotência e resignação, assinalam que só nos restaria contar as horas, assistindo à passagem do tempo e reproduzindo ao infinito os modos de subjetivação dominantes que o atual tempo histórico oferece, ou seja, a vida humana e natural subjugadas ao imperativo do capital.

Se, passados 300 anos, recorrermos à obra de Espinosa para dar consistência ao conceito de sustentabilidade afetiva é porque ali encontramos o afeto como uma ferramenta conceitual que resgata a dimensão política da existência, colocando em evidência a importância dos encontros, com suas composições e decomposições, que se processam na relação entre o humano e o meio ambiente. Tal conceito assinala uma possibilidade de resistência ao cansaço, à resignação e à indiferença que marcam a vida contemporânea.

\section{Referências}

Almeida, F. (2002). O bom negócio da sustentabilidade. São Paulo: Nova Fronteira.

Brundtland, G. H. (Org.). (1991). Nosso Futuro Comum: Comissão Mundial sobre Meio Ambiente e Desenvolvimento. Rio de Janeiro: Editora da Fundação Getúlio Vargas.

Chauí, M. (1995). Espinosa, uma filosofia da liberdade. São Paulo: Editora Moderna.

Chauí, M. (1999). A nervura do real: imanência e liberdade em Espinosa. São Paulo: Companhia das Letras.

Deleuze, G. (1997). Crítica e Clínica. São Paulo: Editora 34.

Deleuze, G. (2002). Espinosa: Filosofia prática. São Paulo: Editora Escuta.

Deleuze, G. (2009). Curso sobre Spinoza (Vincennes, 1978-1981). Fortaleza: Editora UECE.

Deleuze, G. \& Guattari, F. (1992). O que é a filosofia? Rio de Janeiro: Editora 34. 
Deleuze, G. \& Guattari, F. (1972/2010). O anti-Édipo: capitalismo e esquizofrenia. São Paulo: Editora 34.

Diegues, A. C. S. (2010). O mito moderno da natureza intocada. São Paulo: HUCITEC.

Elkington, J. (2001). Canibais com garfo e faca. São Paulo: Makron Books.

Espinosa, B. (1677/1983). Espinosa - Coleção Os Pensadores. São Paulo: Ed. Nova Cultural.

Foladori, G. (2001) Limites do desenvolvimento sustentável. Campinas, SP: Editora da Unicamp, São Paulo: Imprensa Oficial.

Foladori, G. (2002). Avanços e limites da sustentabilidade social. Revista Paranaense de Desenvolvimento, 10(3), 103-113.

Fonseca, T. M. G. (2013). Quando a solidão custa chegar. Mnemosine, 9 (1), 205-211.

Godoy, A. (2008). A menor das ecologias. São Paulo: EDUSP, 2008.

Guattari, F. (1992). Caosmose: um novo paradigma estético. São Paulo: Editora 34.

Guattari, F. (1997). As Três ecologias. Campinas: Papirus.

Guattari, F. \& Rolnik, S. (1996). Micropolítica: cartografias do desejo. Petrópolis: Vozes.

Houaiss, A. (2009). Dicionário da língua portuguesa. Rio de Janeiro: Objetiva.

Kraemer, M. E. P. (2005). Responsabilidade social: uma alavanca para a sustentabilidade. Curitiba: Ambiente Brasil.

Lasch, C. (1987). O Mínimo eu: sobrevivência psíquica em tempos difíceis. São Paulo: Editora Brasiliense.

Lenzi, C. L. (2006). Sociologia Ambiental: risco e sustentabilidade na modernidade. Bauru: Edusc.

Misoczky, M. C. \& Böhm, S. (2012). Do desenvolvimento sustentável à economia verde: a constante investida do capital sobre a natureza. Cadernos EBAPE.BR, 10(3), 546-568.

Rolnik, S. (2003). O ocaso da vítima: para além da cafetinagem da criação e de sua separação da resistência. Revista Ars, 1(2), 79-87.

Stengers, I. (2015). No tempo das catástrofes: resistir à barbárie que se aproxima. São Paulo: Cosac Naif.

Viveiros de Castro, E. (2015). Metafísicas canibais: elementos para uma antropologia pós-estrutural. São Paulo: Cosac Naif.

\section{Endereço para correspondência}

Sonia Regina Vargas Mansano

Universidade Estadual de Londrina

Campus Universitário - Centro de Ciências Biológicas

Departamento de Psicologia Social e Institucional

Rod. Celso Garcia Cid, Km 445, CEP 86051-990, Londrina - PR, Brasil

Endereço eletrônico: mansano@uel.br 


\section{Paulo Roberto de Carvalho}

Universidade Estadual de Londrina

Campus Universitário - Centro de Ciências Biológicas

Departamento de Psicologia Social e Institucional

Rod. Celso Garcia Cid, Km 445, CEP 86051-990, Londrina - PR, Brasil

Endereço eletrônico: paulor@uel.br

Recebido em: 16/11/2015

Reformulado em: 25/05/2016

Aceito para publicação em: 25/09/2016

\section{Notas}

* Doutora em Psicologia Clínica pela PUC/SP.

** Doutor em Psicologia Clínica pela PUC/SP. 